\title{
MOLECULAR CHARACTERIZATION OF HEMOPHILIA A IN SOUTHEAST BULGARIA
}

\author{
Sukarova Stefanovska E ${ }^{1}$, Tchakarova $\mathrm{P}^{2}$, Petkov $\mathrm{GH}^{2}$, Efremov GD ${ }^{1, *}$
}

\begin{abstract}
*Corresponding Author: Professor Dr. Georgi D. Efremov, Research Centre for Genetic Engineering and Biotechnology, Macedonian Academy of Sciences and Arts, Bul. Krste Misirkov 2, POB 428, Skopje 1000, Republic of Macedonia; Tel.: +389-2-3235-411; Fax: +389-2-3115-434; E-mail: gde@manu.edu.mk
\end{abstract}

\begin{abstract}
The results of molecular characterization of Hemophilia A in 50 patients from Southeast Bulgaria are presented. Southern blot analysis for the detection of inversions in intron 22, and polymerase chain reaction (PCR) followed by single strand conformation polymorphism (SSCP) or denaturing gradient gel electrophoresis (DGGE) for screening of the coding sequences of the Factor VIII (FVIII) gene were used. A molecular defect was found in $35(70 \%)$, the most frequent being an inversion in intron 22, found in $19(38 \%)$ patients; an intron 1 inversion was not detected. In one severely affected patient, an Alu insert was found, which disrupted exon 14 at codon 1224. Nucleotide substitutions were found in $15(30 \%)$ patients, the most frequent being an Arg531 $\rightarrow$ Cys missense mutation in exon 11. The same nonsense mutation (codon $-5, C \mathrm{GA}>T \mathrm{GA}$ ) was found in two patients with a severe phenotype. Seven missense mutations (Asn90 $\rightarrow$ Thr, Arg 372 $\rightarrow$ His, Glu456 $\rightarrow$ Val, Tyr473 $\rightarrow$ His, Arg1689 $\rightarrow$ Cys, Arg2159 $\rightarrow$ Cys and Arg2163 $\rightarrow$ His) were detected in isolated families. Two of these (Asn90 $\rightarrow$ Thr and Glu456 $\rightarrow$ Val) are being reported for the first time.
\end{abstract}

Research Centre for Genetic Engineering and Biotechnology, Macedonian Academy of Sciences and Arts, Skopje, Republic of Macedonia

2 Pediatric Clinic, Medical Faculty, Stara Zagora, Bulgaria
Key words: Hemophilia A; Factor VIII (FVIII) gene; Molecular characterization; Inversions; Point mutations

\section{INTRODUCTION}

Hemophilia A is a common X-linked bleeding disorder affecting 1/5,000 males worldwide [1]. It is caused by mutations in the factor VIII (FVIII) gene, leading to a deficiency of, or to a dysfunctional FVIII, an essential cofactor in the factor X activation complex. This gene consists of 26 exons (approximately $9 \mathrm{~kb}$ mRNA) and encodes a 2,351 amino acid precursor protein. This comprises of a leader peptide, three A domains, a B domain and two $\mathrm{C}$ domains. The A domains are flanked by small acidic regions (a1-3) in the sequence: A1-a1-A2-a2B-a3-A3-C1-C2 [2]. During secretion, circulation in plasma and activation of the precursor protein undergoes a series of cleavages that result in the active heterotrimeric FVIII [3].

Factor VIII deficiency is heterogeneous in clinical severity and at the molecular level. The most common molecular defect is an intron 22 inversion which occurs in up to $45 \%$ of severely hemophilic patients. This is caused by recombination between a sequence within intron 22 of the FVIII gene and one of the two homologous regions telomeric to the gene [4]. Another recurrent mutation is the intron 1 inversion which has a frequency of up to $5 \%$ of molecular defects detected in hemophilic patients of different ethnic groups [5]. Other mutations 
are mainly single nucleotide substitutions spread throughout the coding region of the gene, and are peculiar to the individual families [6]. A comprehensive FVIII mutation database and sequence resource site (HAMSTeRS) is available at http:// europium.csc.mrc.ac.uk. Knowledge of the causative molecular defect has become an important tool in hemophilia care with respect to prediction of the clinical course and safe genetic counseling of relatives.

\section{MATERIALS AND METHODS}

Patients. Fifty unrelated patients with Hemophilia A, and members of their families, were studied. Severe and moderate phenotypes were observed in 40 and 10 of the patients, respectively. The clinical severity was determined according to standard criteria, based on the remaining FVIII activity [7]. Blood samples were obtained after informed consent. DNA was isolated from peripheral white blood cells using the classical phenol/chloroform extraction and the ethanol precipitation methods used in our laboratory [8].

Southern Blotting. The intron 22 inversion of the FVIII gene was analyzed by Southern blotting using the $B c l$ restriction enzyme and a $0.9 \mathrm{~kb} E c o \mathrm{RI} /$ SstI fragment of plasmid p482.6 (ATCC), containing a part of the intron 22 homologous sequence. The probe was non radioactively labeled using the Fluorescein Gene Images Labeling and Detection System (GE Healthcare Bio-Sciences AB, Uppsala, Sweden). The same Southern blotting method was used for the determination of gross gene deletions or insertions in the FVIII gene. Genomic DNA was digested with the TaqI restriction enzyme and hybridized with probes A and B representing cDNA of the FVIII gene from exons 1-14 and 14-26, respectively [9].

Polymerase Chain Reaction (PCR), Single Strand Conformation Polymorphism (SSCP) and Denaturing Gradient Gel Electrophoresis (DGGE). Patients in whom an inversion in intron 22 was not found to be a cause of Hemophilia A, were further tested for the presence of single nucleotide changes or small deletions/ insertions in the coding regions of the FVIII gene. The intron 1 inversion was detected using two sets of $\mathrm{PC}$ reactions according to Kemball-Cook et al. [5]. All exons, except exon 14, were separately amplified from genomic DNA by PCR using oligonucleotide primers and cycling conditions as described by David et al. [10] for SSCP or by Diamond et al. [11] for DGGE. The SSCP and DGGE tests were performed on the DeCode System (Bio-Rad Laboratories, Hercules, CA, USA).

DNA Sequencing. To identify the nucleotide substitutions responsible for altered electrophoretic mobility detected by SSCP or DGGE analyses, each of the PCR fragments was sequenced, using the BigDye Terminator v1.1 kit (PE Applied BioSystems, Foster City, CA, USA) on an ABI PRISM ${ }^{\mathrm{TM}} 310$ Genetic Analyzer (PE Applied BioSystems). All sequence changes were confirmed in both strands, and analyzed by alignment with normal sequences in the database.

\section{RESULTS AND DISCUSSION}

The molecular defects we detected in 35 of 50 (70\%) patients, are shown in Table 1.

Inversion in Intron 22. The inversion in intron 22 was identified in 19 patients, all with a severe form of the disease, giving an incidence of $38 \%$ of all screened patients, or $47.5 \%$ (19/40) of those with a severe form (Figure 1). Of these, 12 patients had a distal inversion, or type $1(63.2 \%)$, and $7(36.8 \%)$ had a proximal type of inversion, type 2 . This finding agrees with the global frequency of this defect (23$35 \%$ of all patients studied, and $41-57 \%$ of patients with a severe form of the disease) [12]. The mothers of all patients with this inversion were found to be heterozygous for the inversion. This accords well with the observation that it develops predominantly during male germ cell meiosis [13].

The intron 1 inversion was not detected in any of our patients. After the identification of the intron 1 inversion several years ago [5], a prevalence of $0-5 \%$ was reported [14]. This mutation was not found in 104 unrelated severe Hemophilia A patients from Hungary [15].

Alu Insertion. In one patient with severe disease, we detected an abnormal pattern using the cDNA probe covering exons $14-26$ of the FVIII gene. Instead of a signal from a $5.9 \mathrm{~kb}$ fragment corresponding to exon 14, two prominent bands of $\sim 3.6 \mathrm{~kb}$ and $2.6 \mathrm{~kb}$, respectively, were present on the autoradiogram. This is indicative of an insertion 
Table 1. Molecular characterization of Hemophilia A patients from South East Bulgaria

\begin{tabular}{|l|c|c|}
\hline & $n$ & $\%$ \\
\hline Patients & 50 & 100.0 \\
\hline Inversions in intron 22 & 19 & 38.0 \\
\hline Point mutations & 15 & 30.0 \\
\hline Insertion in FVIII gene & 1 & 2.0 \\
\hline Inversion in intron 1 & 0 & 0.0 \\
\hline Unknown & 15 & 30.0 \\
\hline
\end{tabular}

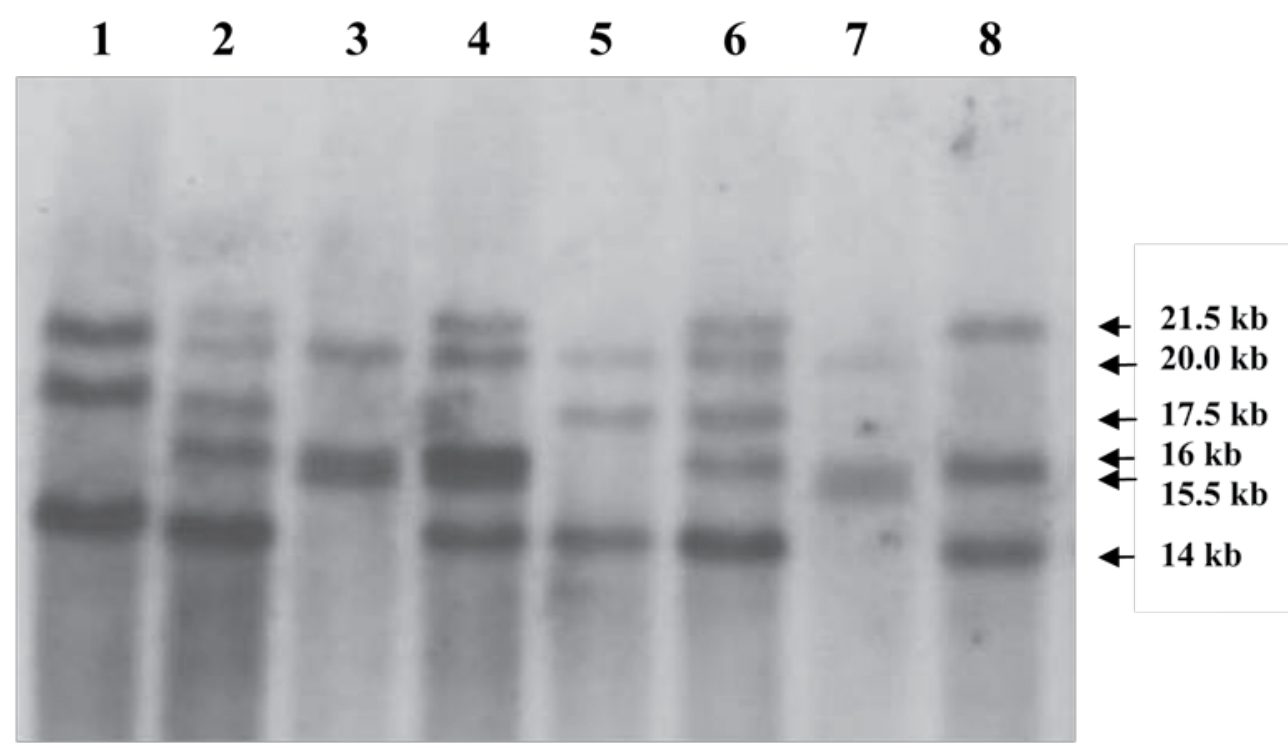

Figure 1. Southern blot analysis for detection of intron 22 inversion in the FVIII gene. Lanes 1 and 5: patients with inversion type 1; lanes 2 and 6: carriers for inversion type 1; lanes 3 and 7. patients with inversion type 2; lane 4: carrier for inversion type 2; lane 8: normal control.

of $\sim 300 \mathrm{bp}$ carrying a novel TaqI site within exon 14. Long-range PCR of the entire exon 14 of the patient, his brother, mother, maternal grandmother and a normal control, confirmed the presence of this inserted sequence of $\sim 300 \mathrm{bp}$, which disrupts the reading frame at methionine 1224 in exon 14, leading to a stop codon within the inserted sequence. Sequence determination demonstrated that the insertion was a full Alu repeat belonging to the $\mathrm{Yb} 8 \mathrm{fam}-$ ily, the youngest family of Alu repetitive sequences [16].

Nucleotide Substitutions. All the other molecular defects we detected were single base substitutions (Table 2). Severe hemophilia was associated with five mutations predicted to cause premature termination or to affect the active site of the molecule. The change at codon -5 (CGA $>$ TGA, Arg $\rightarrow$ Stop), was found in two unrelated, severely affected patients. Haplotyping of the FVIII gene in these two patients revealed the same haplotype, indicating a common founder. Three missense mutations (Arg 372 $\rightarrow$ His; Arg1689 $\rightarrow$ Cys; and Arg2163 $\rightarrow$ His) were associated with severe disease. The Arg372 $\rightarrow$ His mutation in exon 8 and $\operatorname{Arg} 1689 \rightarrow$ Cys in exon 14, destroys the thrombin cleavage site. An Arg2163 $\rightarrow$ His mutation in exon 23 was found in one patient. This mutation has been reported in both severe and moderate Hemophilia A patients (http:// europium. csc.mrc. 
Table 2. Mutations identified in the factor VIII gene among Hemophilia A patients from Southeast Bulgaria

\begin{tabular}{|c|c|c|c|c|c|c|}
\hline Exon & Codon & Domain & Nucleotide Change & Amino Acid Change & Clinical Expression & $n$ \\
\hline 1 & -5 & signal peptide & $\mathrm{CGA}>\mathrm{TGA}$ & $\mathrm{Arg} \rightarrow$ Stop & severe & 2 \\
\hline 3 & 90 & A1 & $\mathrm{AAC}>\mathrm{ACC}$ & Asn $\rightarrow$ Thr & moderate & $1^{\mathrm{a}}$ \\
\hline 8 & 372 & A1 & $\mathrm{CGC}>\mathrm{CAC}$ & Arg $\rightarrow$ His & severe & 1 \\
\hline 9 & 456 & $\mathrm{~A} 2$ & GAA $>$ GTA & $\mathrm{Glu} \rightarrow \mathrm{Val}$ & moderate & $1^{\mathrm{a}}$ \\
\hline 10 & 473 & $\mathrm{~A} 2$ & $\mathrm{TAT}>\mathrm{CAT}$ & $\mathrm{Tyr} \rightarrow \mathrm{His}$ & moderate & 1 \\
\hline 11 & 531 & A2 & $\mathrm{CGC}>\mathrm{TGC}$ & Arg $\rightarrow$ Cys & moderate & 6 \\
\hline 14 & 1689 & A3 & $\mathrm{CGC}>\mathrm{TGC}$ & Arg $\rightarrow$ Cys & severe & 1 \\
\hline 23 & 2159 & $\mathrm{C} 1$ & $\mathrm{CGC}>\mathrm{TGC}$ & Arg $\rightarrow$ Cys & moderate & 1 \\
\hline 23 & 2163 & $\mathrm{C} 1$ & $\mathrm{CGC}>\mathrm{CAC}$ & $\mathrm{Arg} \rightarrow \mathrm{His}$ & severe & 1 \\
\hline
\end{tabular}

${ }^{a}$ These mutations are being reported for the first time.

ac.uk), indicating that it interferes with the molecular stability of the FVIII gene.

All moderate cases were associated with missense mutations in different parts of the coding region (Table 2). The most abundant was an Arg531 $\rightarrow$ Cys in exon 11, which was found in six $(12 \%)$ unrelated patients. All mothers of these patients were carriers for the mutation, and all six patients shared the same haplotype $(B c l \mathrm{I}+/ \mathrm{Y} ; \mathrm{XbaI}+/ \mathrm{Y}$, intron 13 polymorphism $25 / \mathrm{Y}$ and intron $22-20 / \mathrm{Y}$ ) indicating a founder effect. The other mutations (Asn90 $\rightarrow$ Thr,
Glu456 $\rightarrow$ Val, Tyr473 $\rightarrow$ His and Arg2159 $\rightarrow$ Cys) were found in individual families.

Two new mutations of residues highly conserved in murine, porcine and canine FVIII were characterized. An $\mathrm{A} A \mathrm{C}>\mathrm{ACC}$ change at codon 90, exon 3 , or Asn90 $\rightarrow$ Thr, mutation was found in a patient and his cousin, with moderate disease (FVIII $3 \%$ ). The mothers of both were carriers of the mutation, while their maternal grandmother had a normal DNA pattern (Figure 2). The maternal grandfather was not available for study but is clinically
A.

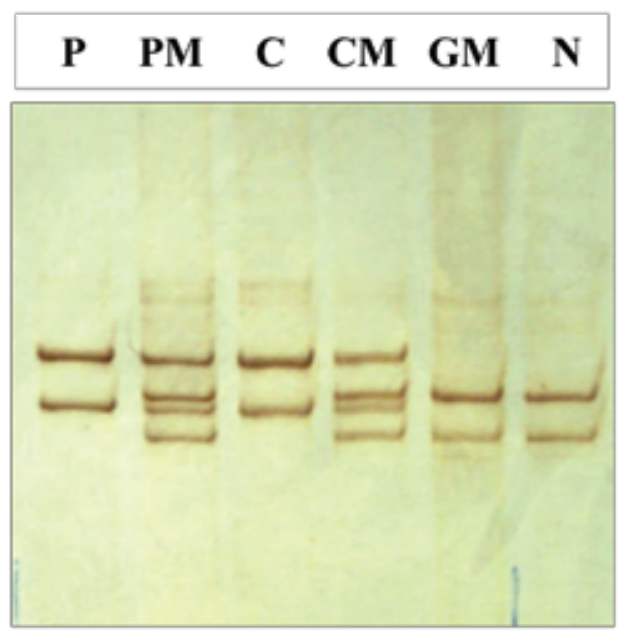

B.

N: TACACT TAAGA ACATGGCT T C C

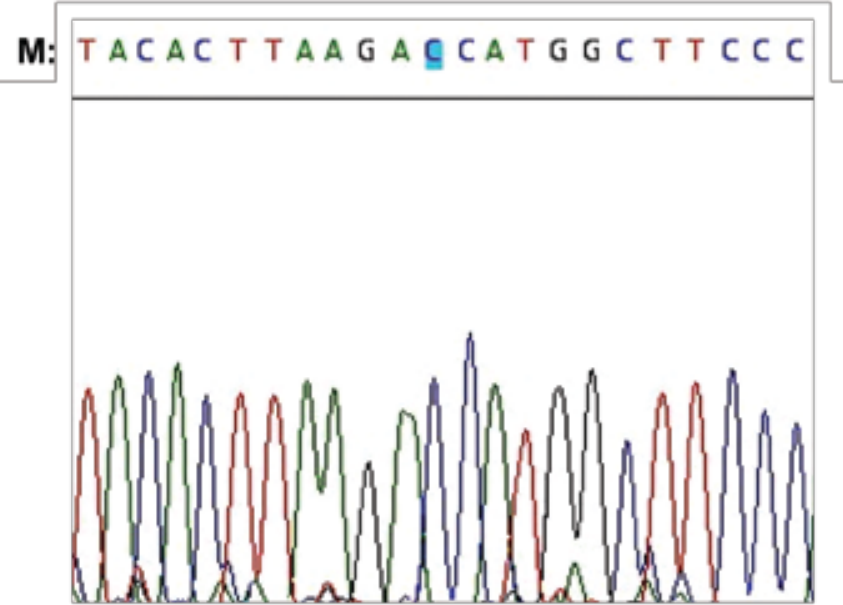

Figure 2. Representative photograph of SSCP analysis (A) and sequencing of abnormal fragment (B) identifying the new mutation $\mathrm{A} A \mathrm{C}>\mathrm{ACC}$ or $\mathrm{Asn} 90 \rightarrow \mathrm{Thr}$ at codon 90 of exon 3. Lanes $\mathrm{P}$ and $\mathrm{C}$ : patient and his cousin; lanes $\mathrm{PM}$ and CM: mothers of patient and cousin; lane GM: maternal grandmother; lane N: normal control. 
A.

B.

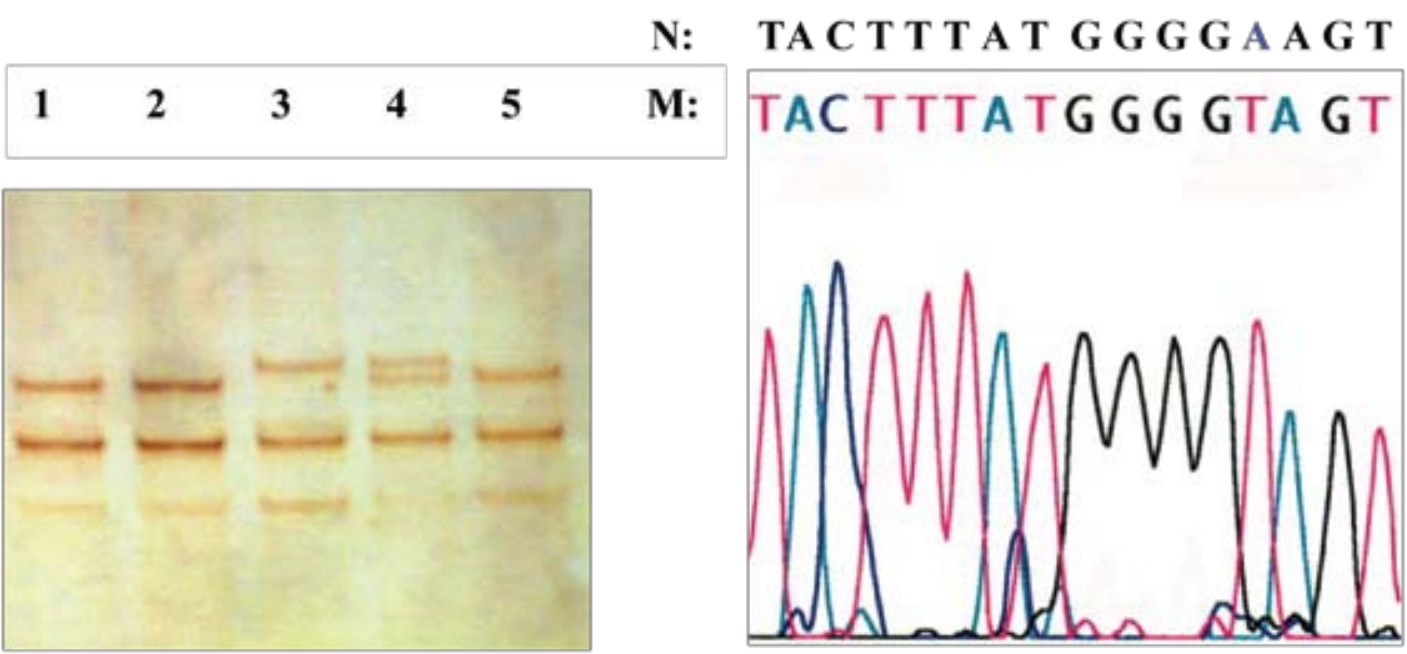

Figure 3. Representative photograph of SSCP analysis (A) and sequencing of abnormal fragment (B) identifying the new mutation $\mathrm{G} A \mathrm{~A}>\mathrm{GTA}$ or Glu456 $\rightarrow$ Val at codon 456, exon 9. Lane 3: patient; lane 4: his mother; lanes 1,2 and 5: normal controls.

normal, thus suggesting a de novo FVIII mutation in his germ cells. A GAA $>$ GTA change in exon 9, or Glu456 $\rightarrow$ Val substitution, was found in a patient with moderate disease (Figure 3). Only one other $G \mathrm{AA}>A \mathrm{AA}$ or Glu $456 \rightarrow$ Lys at this position, has been described in a patient with moderate disease (http://europium.csc.mrc.ac.uk).

The lower frequency of the known mutations is most likely due to the low sensitivity of the screening method used, especially SSCP. Also mutations could reside in regions that were not tested in this study (exon 14, promoter region or the 3' untranslated region)

This is the first comprehensive study of the FVIII gene defects causing Hemophilia A in patients from Southeast Bulgaria. Based upon these results, it appears that carrier detection and prenatal diagnosis is possible in $70 \%$ of affected families. The two new mutations also increase our understanding of the molecular pathology of Hemophilia A.

\section{ACKNOWLEDGMENT}

This study was supported in part by the Ministry of Science of the Republic of Macedonia (No. 40086298) and by the Funds for Science of the Macedonian Academy of Sciences and Arts (No. 09-40/12), Skopje, Republic of Macedonia (both to GDE).

\section{REFERENCES}

1. Bolton-Maggs PHB, Pasi JK. Haemophilia A and B. Lancet 2003; 361(9371): 1801-1809.

2. Wood WI, Capon DJ, Simonsen CC, Eaton DL, Gitschier J, Keyt B, Seebork PH, Smith DH, Hollingshead P, Wion KL, Delwart E, Tuddenham EGD, Vehar GA, Lawn RM. Expression of active human factor VIII from recombinant cDNA clones. Nature 1984; 312(5992): 330-337.

3. Saenko EL, Ananyeva NM, Tuddenham EGD, Kemball-Cook G. Factor FVIII - novel insights into form and function. Br J Haematol 2002; 119(2): 323-331.

4. Lakich D, Kazazian HH Jr, Antonarakis SE, Gitschier J. Inversions disrupting the factor VIII are a common cause for severe Haemophilia A. Nat Genet 1993; 5(3): 236-241.

5. Bagnall RD, Waseem N, Green PM, Giannelli $F$. Recurrent inversion breaking intron 1 of the factor VIII gene is a frequent cause of severe hemophilia A. Blood 2002; 99(1): 168-174.

6. Kemball Cook G, Tuddenham EGD, Wacey AI. The factor VIII structure and mutation resource site HAMSTeRS version 4. Nucleic Acids Res 1998; 26(1): 216-219 (http://europium.csc.mrc. ac.uk)

7. Antonarakis SE, Kazazian HH, Tuddenham EGD. Molecular etiology of factor VIII deficiency 
in hemophilia A. Hum Mutat 1995; 5(1): 1-22.

8. Efremov G.D, Dimovski A.J, PlaseskaKaranfilska D, Simjanovsa L, Sukarova E, Koceva S, Popovski Z. Laboratory Manual, 2nd ed. 1998. ICGEB Affilated Center "Nucleic acid based methods in human and veterinary medicine." Skopje: Macedonian Academy of Sciences and Arts, 1998.

9. Gitschier J, Wood WI, Tuddenham EGD, Shuman MA, Goralka TM, Chen EY, Lawn RM. Detection and sequence of mutations in the factor VIII gene of haemophiliacs. Nature 1985; 315(6018): 427-430.

10. David D, Moreira I, Lalloz MRA, Rosa HAV, Schwaab R, Morais S, Diniz MJ, de Deus G, Camops M, Lavinha J, Johnson D, Tuddenham EGD. Analysis of the essential sequences of the human factor VIII gene in twelve haemophilia A patients with single strand conformation polymorphism. Blood Coagul Fibrinol 1992; 5(2): 257 264.

11. Diamond C, Kogan S, Levinson B, Gitschier J. Amino acid substitutions in a conserved domains of factor VIII and related proteins: study of patients with mild and moderately severe hemophilia A. Hum Mutat 1992; 1(3): 248-257.
12. Antonarakis SE, and a consortium of more than 50 international authors. Factor VIII gene inversions in severe hemophilia A: results of an international consortium study. Blood 1995; 86(6): 2206-2212.

13. Rossiter JP, Young M, Kimberland ML, Hutter P, Ketterling RP, Gitschier J, Horst J, Morris MA, Schaid DJ, de Moerloose P, Sommer SS, Kazazian HH, Antonarakis SE. Factor VIII gene inversions causing severe hemophilia A originate almost exclusively in male germ cells. Hum Mol Genet 1994; 3(7): 1035-1039.

14. Schroder J, El-Maarri O, Schwaab R, Muller CR, Oldenburg J. Factor VIII intron-1 inversion: frequency and inhibitor prevalence. J Thromb Haemost 2006; 4(5): 1141-11413.

15. Andrikovics H, Klein I, Bors A, Nemes L, Marosi A, Varadi A, Tordai A. Analysis of large structural changes of the factor VIII gene, involving intron 1 and 22, in severe hemophilia A. Haematologica 2003; 88(7): 778-784.

16. Sukarova E, Dimovski AJ, Tchacarova P, Petkov GH, Efremov GD. An Alu insert as the cause of a severe form of hemophilia A. Acta Haematol 2001, 106(3): 126-129. 